\title{
PENINGKATAN KUALITAS HIDUP SEHAT DAN PENCEGAHAN PENYAKIT BERBASIS LINGKUNGAN MELALUI PELATIHAN KADER DAN REMAJA SERTA PERBAIKAN SARANA SANITASI
}

\author{
Mei Ahyanti ${ }^{1}$, Sri Ujiani ${ }^{2}$, Helmi Yenie ${ }^{3}$, I Gusti Ayu Mirah W'3, Tori Rihiantoro ${ }^{4}$, Ririn Sri \\ Handayani $^{4}$, Yustin Nur Khoiriyah ${ }^{2}$ \\ ${ }^{1}$ Prodi D4 Kesehatan Lingkungan Poltekkes Tanjungkarang \\ ${ }^{2}$ Prodi D4 Analis Kesehatan Poltekkes Tanjungkarang \\ ${ }^{3}$ Prodi D4 Kebidanan Tanjuungkarang Poltekkes Tanjungkarang \\ ${ }^{4}$ Prodi D4 Keperawatan Tanjungkarang Poltekkes Tanjungkarang \\ Penulis Korespodensi : mei.ahyanti@gmail.com
}

\begin{abstract}
Abstrak
Permasalahan kesehatan di masyarakat semakin kompleks. Permasalahan penyakit menular belum terselesaikan, sudah makin marak penyakit tidak menular. Permekes RI No. 36 tahun 2016 pasal 1 menyebutkan bahwa Penyelenggaraan Program Indonesia Sehat dengan Pendekatan Keluarga. Desa II Sukasari Desa Sukadadi Kecamatan Gedong Tataan Kabupaten Pesawaran Provinsi Lampung merupakan salah satu daerah dengan permasalahan komplek. Dengan permasalahan kesehatan yang ada dimasyarakat dibutuhkan kesadaran dan keterampilan masyarakat dalam melakukan upaya-upaya pencegahan dan pengendalian terhadap kejadian penyakit agar tidak semakin berat. Dalam mencapai tujuan tersebut, memerlukan peranan dari berbagai tenaga kesehatan secara terintegrasi dari berbagai disiplin ilmu berbeda yang memiliki kompetensi dan bekerja secara team work.

Pelaksanaan pengabdian masyarakat Masyarakat di Desa Sukadadi Kecamatan Gedong Tataan Kabupaten Pesawaran diawali dengan penyamaan persepsi, pelatihan kader dan pendampingan dalam pembuatan sarana sanitasi. Terjadi perbedaan hasil pengukuran pengetahuan dan sikap antara sebelum dan setelah kegiatan pelatihan menunjukkan keberhasilan kegiatan pelatihan dan terbangun satu buah jamban keluarga sederhana sehat sebagai percontohan
\end{abstract}

Kata kunci: pelatihan, jamban sederhana, keterampilan

\section{Pendahuluan}

Permasalahan kesehatan di masyarakat semakin kompleks. Permasalahan penyakit menular belum terselesaikan, sudah makin marak penyakit tidak menular. Permekes RI No. 36 tahun 2016 pasal 1 menyebutkan bahwa Penyelenggaraan Program Indonesia Sehat dengan Pendekatan Keluarga.

Desa II Sukasari Desa Sukadadi Kecamatan Gedong Tataan Kabupaten Pesawaran Provinsi Lampung merupakan salah satu daerah dengan permasalahan komplek. Data yang bersumber dari unit Pengabdian Masyarakat Politeknik Kesehatan Tanjungkarang (2016), Desa Sukadadi memiliki jumlah penduduk 2.402 jiwa dengan jenis kelamin laki-laki dan 2.344 jiwa dengan jenis kelamin perempuan yang tersebar dalam 10 Dusun. (Unit PPM, 2016)

Fasillitas utama dan pendukung telah dimiliki oleh desa tersebut, namun masih terdapat data kesakitan/masalah kesehatan. Gangguan kesehatan yang dialami diantaranya adalah kejadian penyakit diare, partus lama, produksi ASI, lecet putting susu, hepatitis, bayi baru lahir sakit, cakupan ASI eksusif baru 40\%, Imunisasi dasar lengkap 90\%, bawah garis merah 2 orang. Hasil pengabdian masyarakat yang telah dilaksanakan pada bulan April sampai dengan Juni 2018 diperoleh informasi terdapat anggota keluarga yang mengalami diare, diabetes mellitus, hipertensi, dan jantung. (Ujiani, dkk, 2018)

Dengan permasalahan kesehatan yang ada dimasyarakat dan semakin komplek, dibutuhkan kesadaran dan keterampilan masyarakat dalam melakukan upaya-upaya pencegahan dan pengendalian terhadap kejadian penyakit agar tidak semakin berat. Dalam mencapai tujuan tersebut, memerlukan peranan dari berbagai tenaga kesehatan secara terintegrasi. artinya, perlu dilakukan oleh beberapa tenaga kesehatan dengan 
disiplin ilmu berbeda yang memiliki kompetensi dan bekerja secara team work.

\section{Bahan dan Metode}

Kegiatan pengabdian masyarakat Dosen Program Diplima IV Politeknik Kesehatan Kemenkes Tanjungkarang terbagi dalam dua kegiatan. Kegiatan pertama pelatihan kader dan masyarakat menggunakan bahan modul pelatihan yang disusun oleh dosen tim pengabdian kepada masyarakat dan peralatan yang digunakan adalah laptop, proyektor serta prasarana milik Madyasah Ibtidaiyah Desa Sukadadi. Kegiatan kedua pendampingan perbaikan sarana jamban keluarga percontohan, menggunakan bahan Asbes, kayu balok, kasau, paku, semen, pintu jamban, pasir dan kloset, sedangkan peralatan yang digunakan palu, gergaji, ember, dan sendok semen. Metode dalam pelaksanaan pengabdian kepada masyarakat didahului dengan penyamaan persepsi dengan kader, masyarakat dan kepala dusun setempat, dilanjutkan dengan pelatihan pengukuran antropometri bayi dan balita serta pelatihan pengukuran gula darah dan $\mathrm{Hb}$ kepada Kader kesehatan, pelatihan Bantuan Hidup Dasar kepada Remaja Islam Masjid/Karang Taruna, pencegahan penyakit menular kepada kader dan masyarakat dan pendampingan kepada masyarakat dalam pembuatan sarana sanitasi.

\section{Hasil dan Pembahasan}

Rapat koordinasi untuk membahas kesiapan kegiatan pengabdian kepada masyarakat dilaksanakan pada tanggal 26 September 2018 bertempat di Prodi D4 Kebidanan Tanjungkarang. Pengurusan perijinan ke Kepala Desa Sukadadi Kecamatan Gedong Tataan sekaligus penyamaan persepsi dengan kepala dusun dan kader kesehatan. Kegiatan dilaksanakan pada tanggal 28 September 2018. Pelatihan pengukuran antropometri dalam memantau tumbuh kembang bayi dan balita dilaksanakan pada tanggal 11 Oktober 2018 bertempat di Madrasah Ibtidaiyah Desa Sukadadi. Pelatihan pengukuran tekanan darah, gula darah dan haemoglobin dalam upaya deteksi dini terhadap risiko penyakit tidak menular dilaksanakan pada tanggal 24 Oktober 2018 bertempat di Madrasah Ibtidaiyah Desa Sukadadi. Pelatihan bantuan hidup dasar dan pencegahan penyakit menular dilaksanakan tanggal 11 November 2018 bertempat di Madrasah Ibtidaiyah Desa Sukadadi. Pendampingan perbaikan sarana sanitasi dilaksanakan pada tanggal 11, 17, 21, 24, 27 Oktober dan 08 November 2018 bertempat di kediaman Bapak Maman Sukarman (Kepala Dusun Sukasari).

Tabel 1 menggambarkan hasil pre test dan postest mintra pengabdian masyarakat pada kegiatan pelatihan.

Tabel 1.

Distribusi mitra pengabmas berdasarkan pengetahuan di Dusun II Sukasari Desa Sukadadi Kecamatan Gedong Tataan Kabupaten Pesawaran Tahun 2018

\begin{tabular}{|c|c|c|c|c|c|c|c|c|c|}
\hline & \multirow[t]{2}{*}{ Parameter } & \multirow[t]{2}{*}{ Mean } & \multirow{2}{*}{$\begin{array}{c}\text { Std. } \\
\text { Deviation }\end{array}$} & \multirow[b]{2}{*}{$\begin{array}{l}\text { Std. Error } \\
\text { Mean }\end{array}$} & \multicolumn{2}{|c|}{$\begin{array}{l}\text { 95\% Confidence } \\
\text { Interval of the } \\
\text { Difference }\end{array}$} & \multirow[b]{2}{*}{$\mathrm{t}$} & \multirow[b]{2}{*}{$\mathrm{df}$} & \multirow[b]{2}{*}{$\begin{array}{l}\text { Sig. }(2- \\
\text { tailed) }\end{array}$} \\
\hline & & & & & Lower & Upper & & & \\
\hline Pair 1 & $\begin{array}{l}\text { antropometri pre test - } \\
\text { antropometri post }\end{array}$ & -3.400 & 2.472 & .451 & -4.323 & -2.477 & -7.534 & 29 & .000 \\
\hline Pair 2 & $\begin{array}{l}\text { deteksi dini PTM pre test - } \\
\text { Deteksi dini PTM post test }\end{array}$ & -3.733 & 2.625 & .479 & -4.714 & -2.753 & -7.789 & 29 & .000 \\
\hline Pair 3 & $\begin{array}{l}\text { Bantuan Hidup dasar pre test - } \\
\text { bantuan hidup dasar post test }\end{array}$ & -4.600 & 3.069 & .560 & -5.746 & -3.454 & -8.209 & 29 & .000 \\
\hline Pair 4 & $\begin{array}{l}\text { Pencegahan Penyakit menular } \\
\text { pre test - Pencegahan penyakit } \\
\text { menular Post test }\end{array}$ & -2.633 & 2.327 & .425 & -3.502 & -1.765 & -6.200 & 29 & .000 \\
\hline
\end{tabular}

Pada tabel 1 didapatkan hasil pengujian statistik terhadap pengetahuan mitra pengabmas, diperoleh $\mathrm{p}$ value pada pelatihan antropometri $(0,000)$, pelatihan deteksi dini penyakit tidak menular $(0,000)$, bantuan hidup dasar $(0,000)$ dan pencegahan penyakit menular $(0,000)$, hasil tersebut kurang dari $\alpha(0,05)$ artinya terdapat perbedaan yang bermakna antara nilai sebelum dan setelah dilaksanakan kegiatan pelatihan. diperoleh $\mathrm{t}$ hitung dengan nilai negatif, maka dapat disimpulkan bahwa nilai rata-rata pengetahuan 
setelah pelatihan lebih tinggi dibandingkan dengan sebelum pelatihan.

Pelatihan merupakan salah satu metode yang dapat dilakukan sebagai upaya perubahan pemahaman atau pengetahuan masyarakat tentang pentingnya hidup sehat serta memberikan kemampuan agar masyarakat dapat melakukan deteksi dini terhadap potensial atau risiko penyakit tidak menular dan penyakit menular serta tindakan pencegahannya. Dengan adanya pemahaman dan peningkatan keterampilan tersebut diharapkan masyarakat dapat mandiri dalam hal menjaga kesehatannya.

Sebagai pemantapan terhadap hasil kegiatan pelatihan, peserta pelatihan diberikan kesempatan untuk melakukan pengukuran antropometri terhadap bayi dan balita, pemeriksaan tekanan darah, gula darah dan kadar haemoglobin dalam darah serta melakukan praktik bantuan hidup dasar. Adapun hasilnya dapat disajikan pada tabel 2 .

Tabel 2.

Distribusi hasil pengukuran antropometri pada kegiatan pelatihan di Dusun II Sukasari Desa Sukadadi Kecamatan Gedong Tataan Kabupaten Pesawaran Tahun 2018

\begin{tabular}{|c|c|c|c|c|c|c|c|}
\hline No & Nama Pemeriksa & $\begin{array}{c}\text { Bayi/Balita yang } \\
\text { diperiksa }\end{array}$ & $\begin{array}{l}\text { Umur } \\
\text { (tahun) }\end{array}$ & $\begin{array}{c}\text { Berat } \\
\text { Badan } \\
(\mathrm{Kg})\end{array}$ & $\begin{array}{l}\text { Tinggi } \\
\text { Badan } \\
(\mathrm{cm})\end{array}$ & $\begin{array}{l}\text { Lingkar } \\
\text { Lengan } \\
\quad(\mathrm{cm})\end{array}$ & $\begin{array}{c}\text { Lingkar } \\
\text { kepala }(\mathrm{cm})\end{array}$ \\
\hline 1. & Helmi Yenie & Tiara & 1 & 8,5 & 68,8 & 10 & 45 \\
\hline 2. & I Gusti Ayu M & Firlia & 1 & 10,2 & 70,1 & 14 & 46 \\
\hline 3. & Masria & Zunija & 4 & 12,0 & 94,1 & 10 & 49 \\
\hline 4. & Siti Aminah & Aldo & 3 & 12,7 & 87,7 & 11 & 50 \\
\hline 5. & Yeyet Kurniasih & Nina & 5 & 18,0 & 100,5 & 11 & 51 \\
\hline 6. & Edis Wijayanti & Faza & 5 & 19,3 & 104,5 & 11 & 50 \\
\hline 7. & Buniah & Dima & 1 & 10,5 & 71,2 & 9,5 & 47 \\
\hline 8. & Sri Pujiastuti & Intan & 1 & 11,3 & 70,9 & 10 & 47,5 \\
\hline 9. & Titik Farida & Bayu & 2 & 9,9 & 80,5 & 10 & 48 \\
\hline 10. & Sutini & Rizki & 3 & 12,4 & 82,1 & 10 & 50,5 \\
\hline
\end{tabular}

Dari tabel diatas dapat dijelaskan bahwa tumbuh kembang anak di Dusun II Sukasari Desa Sukadadi Kecamatan Gedong Tataan Kabupaten Pesawaran tergolong normal jika dibandingkan dengan standar menurut Keputusan Menteri Kesehatan Republik Indonesia Nomor 1995/Menkes/SK/XII/2010 dan sesai dengan

\section{Tabel 3.}

Distribusi hasil pemeriksaan tekanan darah, gula darah dan Hemoglobin $(\mathrm{Hb})$ pada kegiatan pelatihan di Dusun II Sukasari Desa Sukadadi Kecamatan Gedong Tataan Kabupaten Pesawaran Tahun 2018

\begin{tabular}{lllccc} 
No & NAMA PEMERIKSA & \multicolumn{1}{c}{$\begin{array}{c}\text { NAMA YANG } \\
\text { DIPERIKSA }\end{array}$} & $\begin{array}{c}\text { Tekanan Darah } \\
(\mathrm{mmHg})\end{array}$ & $\begin{array}{c}\text { Gula darah } \\
(\mathrm{mg} / \mathrm{dl})\end{array}$ & $\mathrm{Hb}(\mathrm{g} / \mathrm{dl})$ \\
\hline 1. & Hima & Buniah & $117 / 80$ & 182 & 10,6 \\
\hline 2. & Masria & Edis Wijayanti & $90 / 75$ & 93 & 12,3 \\
\hline 3. & Siti Aminah & Yeyet Kurniasih & $132 / 92$ & 110 & 11,6 \\
\hline
\end{tabular}

ambang batas status gizi anak. Status gizi anak penting, dalam menggambarkan status kesehatan anak.

Selanjutnya hasil pemeriksaan tekanan darah, gula darah dan kadar haemoglobin dalam darah dapat disajikan sebagai berikut : 


\begin{tabular}{llllll}
\hline 4. & Yeyet Kurniasih & Siti Aminah & $141 / 82$ & 105 & 12,7 \\
\hline 5. & Edis Wijayanti & Masria & $107 / 66$ & 104 & 12,0 \\
\hline 6. & Buniah & Sri Pujiastuti & $125 / 84$ & 110 & 12,2 \\
\hline 7. & Sri Pujiastuti & Buniah & $150 / 94$ & 109 & 13,4 \\
\hline 8. & Titik Farida & Ali Udin & $142 / 83$ & 112 & 12,4 \\
\hline 9. & Sutini & Sri Pujiastuti & $120 / 86$ & 100 & 13,3 \\
\hline 10. & Masria & Yeyet Kurniasih & $107 / 66$ & 136 & 13,3 \\
\hline 11. & Bunia & Rohayati & $117 / 83$ & 122 & 12,3 \\
\hline 12. & Dewi Ariani & Listiana & $107 / 80$ & 126 & 13,8 \\
\hline 13. & Amat Yani & Aliyuddin Warja & $125 / 85$ & 123 & 15,3 \\
\hline 14. & Sri Ujiani & Ridwan & $140 / 98$ & 126 & 14,4 \\
\hline 15. & Mei Ahyanti & Hima & $120 / 80$ & 126 & 13,3 \\
\hline 16. & Sri Ujiani & Masria & $114 / 76$ & 130 & 12,3 \\
\hline 17. & Hima & Rohayati & $121 / 81$ & 136 & 13,6 \\
\hline 18. & Rohayati & Titik Farida & $152 / 101$ & 105 & 12,2 \\
\hline 19. & Titik Farida & Dewi Ariani & $120 / 81$ & 128 & 13,4 \\
\hline 20. & Zerlin & Sutini & $122 / 80$ & 125 & 11,7 \\
\hline
\end{tabular}

Tabel diatas menunjukkan hasil pemeriksaan pada kegiatan pelatihan yang dilakukan oleh kader. Pada pelatihan ini kader dan masyarakat telah memiliki kemampuan melakukan pengukuran terhadap tekanan darah, gula darah dan kadar haemoglobin dalam darah dalam ranga deteksi dini penyakit tidak menular. Dari hasil pengukuran tampak 5 orang memiliki tekanan darah tinggi yaitu diatas $100 / 80 \mathrm{mmHg}$, gula darah normal yaitu dibawah $200 \mathrm{mg} / \mathrm{dl}$. Untuk pengukuran haemoblobin dalam darah, hasil pengukuran cenderung normal, hanya ditemukan 1 orang wanita yang memiliki haemoglobin rendah yaitu kurang dari $12 \mathrm{~g} / \mathrm{dl}$.

Pengukuran kepuasan mitra pengabdian kepada masyarakat dilakukan diakhir kegiatan pelatihan yaitu pada tanggal 11 November 2018. Kegiatan ini untuk mengevaluasi keberhasilan dan kepuasan mitra terhadap kegiatan pelatihan yang telah dilaksanakan. Hasilnya dapat digambarkan sebagai berikut :

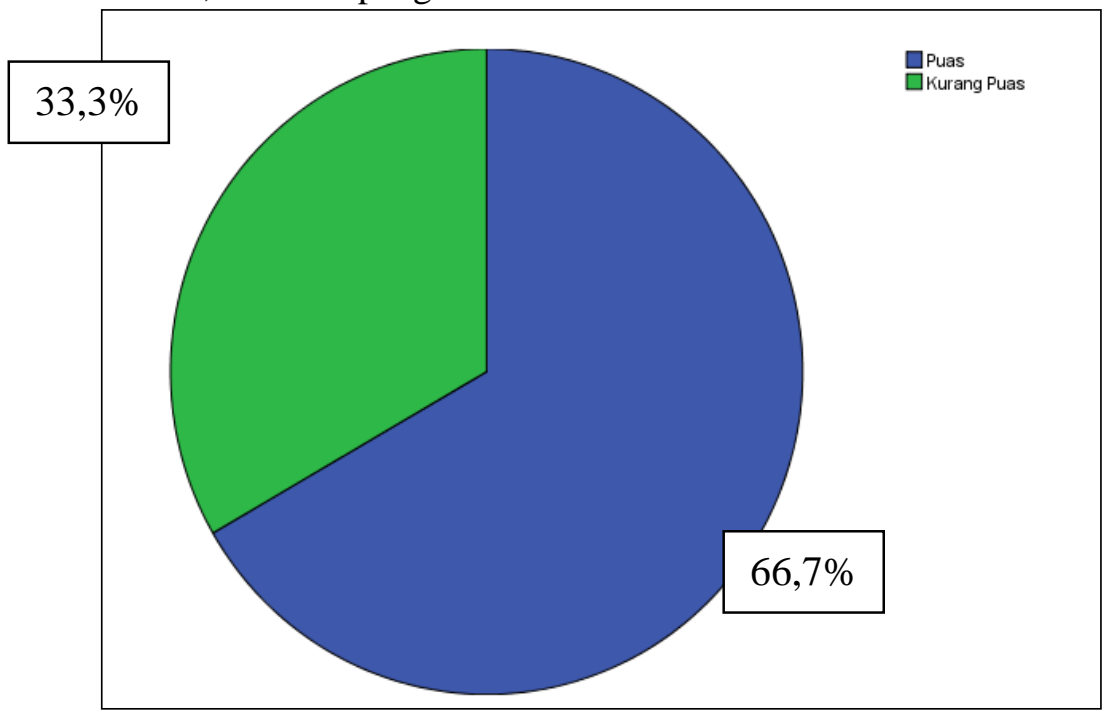

Gambar 1.Distribusi tingkat kepuasan mitra pengabmas di Dusun II Sukasari Desa Sukadadi Kecamatan Gedong Tataan Kabupaten Pesawaran Tahun 2018 
Pada gambar 1 terlihat sebagian besar $(66,7 \%)$ masyarakat merasa puas dengan kegiatan pengabdian masyarakat oleh Dosen Poltekkes Tanjungkarang. Dengan adanya kegiatan pengabdian masyarakat, mereka dapat meningkatkan pengetahuan tentang pentingnya hidup sehat dan memiliki kemandirian dalam bidang kesehatan. Terdapat 33,3\% masyarakat yang merasa kurang puas dengan adanya kegiatan pengabdian kepada masyarakat disebabkan belum bisa terakomodir seluruh harapan masyarakat seperti belum tersedianya sarana pemeriksaan ibu hamil dan gedung posyandu serta keinginan masyarakat untuk memiliki sarana air bersih sendiri.

\section{Simpulan}

Tenaga kesehatan memiliki peran yang sangat penting dalam penyelesaian permaslahan kesehatan yang ada dimasyarakat. Keterlibatan antar beberapa profesi diperlukan dalam rangka peningkatan kesehatan melalui pendekatan keluarga, oleh karena itu kelompok II IPC (Interprofesional Collaboration) bergabung bersama masyarakat dalam penyelesaian masalah kesehatan yang ada. Namun disadari masyarakat harus dapat mandiri dalam hal memantau kesehatan keluarganya, sehingga kegiatan pelatihan dilaksanakan sebagai upaya kemandirian masyarakat. Kegiatan pengabdian kepada masyarakat yang dilaksanakan di Dusun II Sukasari Desa Sukadadi Kecamatan Gedong Tataan Kabupaten Pesawaran telah berjalan dengan lancar, kegiatan dilakukan dalam bentuk pelatihan dan pembangunan sarana sanitasi jamban.

\section{Ucapan Terima Kasih}

Ucapan terima kasih kami sampaikan kepada Direktur dan Kepala Uni Penelitian dan Pengabdian Kepada Masyarakat Politeknik Kesehatan Tanjungkarang yang telah memfasilitasi kegiatan ini.

\section{Daftar Pustaka}

Depkes RI, 2005. Buku Pedoman Pengendalian Penyakit Diare. Direktorat Jenderal PP dan PL, Jakarta.

Depkes RI, 2002. Pedoman Pemberantasan Penyakit ISPA, Ditjen PPM dan PLP, Jakarta.
Junaidi, Iskandar, 2010. Penyakit Paru dan Saluran Pernafasan, PT.Bhuana Ilmu Populer, Kelompok Gramedia, Jakarta.

Nursalam, 2005. Asuhan Keperawatan Bayi dan Balita (untuk perawat dan bidan), edisi pertama, Salemba Medika, Jakarta.

Perka BNPB RI No. 1407 tahun 2014 tentang Tata Cara Pemberian Bantuan Pemenuhan Kebutuhan Dasar.

Permekes RI No. 36 tahun 2016

Ujiani, dkk. 2018. Pemberdayaan Masyarkat Dalam Deteksi Dini Kesehatan Keluarga di Dusun 2 Sukasari Desa Sukadadi Kecamatan Gedong Tataan Kabupaten Pesawaran. Laporan pengabdian Kepada Masyarakat. Poltekkes Tanjungkarang, Bandar Lampung 